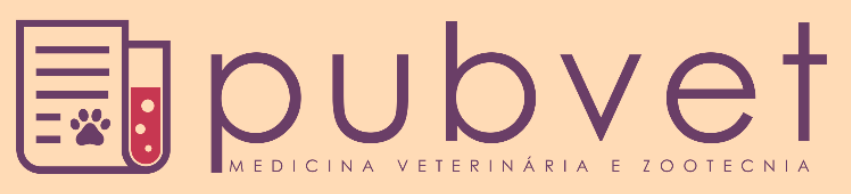

https://doi.org/10.31533/pubvet.v13n01a251.1-7

\title{
Aspectos relacionados a retenção de placenta em vacas
}

\author{
Ítalo Câmara de Almeida ${ }^{\oplus}$, Larissa Marchiori Sena ${ }^{2 *} \bullet$, Vinicius Maretto ${ }^{3}$, Carla Braga Martins ${ }^{4} \bullet$ \\ ${ }^{1}$ Médico Veterinário, Auxiliar, Universidade Federal do Espírito Santo (UFES), Alegre, ES, Brasil. \\ ${ }^{2}$ Médica Veterinária, Mestra em Ciências Veterinárias, Residente em Patologia Clínica Veterinária, UFES, Alegre, ES, Brasil. \\ ${ }^{3}$ Médico Veterinário, Mestrando, Universidade Estadual do Norte Fluminense Darcy Ribeiro, Campus, RJ, Brasil. \\ ${ }^{4}$ Docente do Departamento de Medicina Veterinária, Centro de Ciências Agrárias e Engenharias, UFES, Alegre, ES, Brasil. \\ *Autor para correspondência, E-mail: Imsmvet@gmail.com
}

\begin{abstract}
Resumo. A retenção placentária está entre as principais enfermidades que acometem bovinos no pós-parto. Caracteriza-se pela falha na expulsão das membranas fetais, que ocorre durante o terceiro estágio do trabalho de parto. Apresenta etiologia multifatorial, estando associada a abortamentos, doenças metabólicas ou infecciosas, distocias, partos gemelares, indução do parto, intervenções obstétricas, além de fatores específicos relacionados ao manejo na propriedade, entre outros. Devido a importância econômica e o grande acometimento no rebanho bovino mundial, objetivou-se a realização de uma revisão de literatura abordando os principais temas inerentes à retenção de placenta em vacas, bem como os aspectos relacionados a esta enfermidade.
\end{abstract}

Palavras chave: bovinos, distocia, pós-parto

\section{Aspects related to retention of placenta in cows}

Abstract. The placental retention is among the main diseases that affect bovines in the postpartum period. It is characterized by failure to expel fetal membranes, which occurs during the third stage of labor. It presents multifactorial etiology, being associated with abortions, metabolic or infectious diseases, dystocias, twin births, labor induction, obstetric interventions, as well as specific factors related to property management, among others. Due to the economic importance and the great affection in the world's cattle herd, the objective was to carry out a literature review addressing the main issues inherent to the retention of placenta in cows, as well as the aspects related to this disease.

Keywords: bovine, dystocia, postpartum

\section{Aspectos relacionados con la placenta retenida en vacas}

Resumen. La retención placentaria está entre las principales enfermedades que afectan a los bovinos en el posparto. Se caracteriza por la falla en la expulsión de las membranas fetales, que ocurre durante la tercera etapa del trabajo de parto. Presenta etiología multifactorial, estando asociada a abortos, enfermedades metabólicas o infecciosas, distocias, partos gemelares, inducción del parto, intervenciones obstétricas, además de factores específicos relacionados al manejo en la propiedad, entre otros. Debido a la importancia económica y a su frecuencia en el rebaño bovino mundial, se objetivó la realización de una revisión de literatura abordando los principales temas inherentes a la retención de placenta en vacas, así como los aspectos relacionados a esta enfermedad.

Palabras clave: ganado, distocia, posparto 


\section{Introdução}

Aproximadamente $75 \%$ das enfermidades que acometem vacas leiteiras acontecem no período de transição, da primeira semana que antecede o parto até a terceira semana pós-parto. Neste contexto, enfermidades relacionadas ao trato reprodutivo, como a retenção placentária, podem prejudicar a produção de leite, bem como afetar a eficiência reprodutiva dos animais (Nobre et al., 2018). A retenção de placenta é uma falha na expulsão das membranas fetais, que ocorre durante o terceiro estágio do trabalho de parto. É considerada uma complicação comum em ruminantes, principalmente em fêmeas bovinas, devido o tipo de placenta cotiledonária encontrada nesta espécie (Pereira et al., 2010). Em condições de normalidade, a placenta deve ser expulsa de 8 a 12 horas após o nascimento do feto e a não expulsão neste período pré-determinado caracteriza a enfermidade (Camargos et al., 2013). No entanto, na prática, a definição mais comumente utilizada para placenta retida é a presença das membranas fetais por 24 horas ou mais após o parto (Markusfeld, 1984).

Vários fatores de risco têm sido relacionados com retenção placentária em vacas. Esses incluem distocias, natimortos, nascimentos múltiplos, ordem de parição, tempo de gestação, época do parto, nutrição e deficiência imunológica (Laven \& Peters, 1996). Além das perdas econômicas devido aos gastos com medicamentos, redução da fertilidade e produção leiteira, a ocorrência de retenção de placenta pode predispor o animal acometido a outras enfermidades associadas como metrite e mastite clínica, o que pode elevar ainda mais os custos de produção (Fernandes et al., 2000). Dessa forma, devido a importância econômica e o grande acometimento no rebanho bovino mundial, objetivou-se a realização de uma revisão de literatura abordando os principais temas inerentes à retenção de placenta em vacas, bem como os aspectos relacionados a esta enfermidade.

\section{Fisiologia da liberação placentária}

O desenvolvimento da retenção de placenta é considerado multifatorial. A incidência pode variar de acordo com cada rebanho. Podem estar associadas a esta enfermidade: abortamentos, doenças metabólicas ou infecciosas, hipocalcemia, distocia, partos gemelares, indução do parto, intervenções obstétricas, duração da gestação, estação do ano, nutrição, idade da vaca e fatores específicos relacionados ao manejo em cada propriedade (Nobre et al., 2012). Além dos fatores citados acima, quaisquer tipos de estresse sofrido pela gestante como: manejo inadequado, transporte, calor, lotação excessiva, vacinações, mudanças bruscas de dieta e sexo do feto (gestações de machos podem causar maior índice de retenção devido ao maior tamanho do feto) também estão relacionados ao desenvolvimento da enfermidade (Pereira et al., 2010). Entretanto, a maior parte dos casos de retenção placentária nos bovinos é provocada pela falência do mecanismo de separação das carúnculas maternas dos cotilédones fetais, e não por falência do mecanismo de expulsão das membranas placentárias (Horta et al., 2010).

A placenta deve permanecer aderida ao útero materno para manter a troca gasosa e aporte de nutrientes necessários para o sucesso da manutenção da gestação. No momento do parto, esta deve separar-se rapidamente do útero, para que possa ser liberada em tempo hábil, antes do fechamento da cérvix (Prestes \& Landim-Alvarenga, 2017). O mecanismo que leva à separação da placenta inicia-se durante os últimos meses de gestação. As carúnculas tornam-se colageneizadas até o momento do parto, sendo que, alguns dias antes, já é possível observar um distanciamento entre as mesmas e os cotilédones. Linfócitos e outras células com função fagocítica são atraídos para a região cotiledonária por um fator quimiotático, estas células tem a função de reduzir o tecido materno nas criptas uterinas facilitando o desprendimento da placenta. Além da migração de celular, os neutrófilos promovem uma resposta imune antiplacentária (Horta et al., 2010). No último mês de gestação, na fase final de maturação dos placentomas, é necessário que ocorra aumento das concentrações plasmáticas de progesterona e estradiol, pois níveis cronicamente baixos, sobretudo de progesterona, prejudicam a maturação dos placentomas e consequentemente o desprendimento dos mesmos (Grunert et al., 2005).

Durante o parto, iniciam-se os fatores mecânicos de eliminação placentária. Durante a fase de expulsão do feto, os primeiros sinais de separação mecânica se tornam evidentes na vizinhança do pedículo caruncular. Com as contrações uterinas, as carúnculas são pressionadas sob o feto, o que gera alterações em sua forma e desprendimento das mesmas (Gross et al., 1986). Com a expulsão do feto e o rompimento do cordão umbilical, gera-se uma isquemia placentária, reduzindo a área superficial do 
epitélio coriônico, facilitando a separação da placenta, que será concluída pelas contrações uterinas pósparto (Prestes \& Landim-Alvarenga, 2017). Tais contrações auxiliam na modificação placentária, bem como na involução uterina, diminuindo o volume caruncular, contribuindo assim, para expulsão total das membranas fetais (Grunert et al., 2005).

\section{Patogenia da doença}

Aproximadamente $66 \%$ dos casos de retenção placentária estão relacionados a falhas nos mecanismos de maturação dos placentomas (Prestes \& Landim-Alvarenga, 2017). No entanto, casos de retenção de placenta também ocorrem devido a dificuldade no desprendimento dessas estruturas (Agrimani et al., 2011). Um importante mecanismo celular está envolvido no processo de liberação das membranas fetais. Neste contexto, vacas que apresentam retenção de placenta possuem além de uma menor quantidade de neutrófilos e linfócitos, a atividade metabólica destas células podem apresentar falhas quimiotáticas, de maneira que não há recrutamento de leucócitos para os placentomas, não ocorrendo à resposta inflamatória necessária para a expulsão da placenta (Fernandes et al., 2000). Esta deficiência nos mecanismos de defesa intrínseca do útero da fêmea bovina além de desencadearem falhas na expulsão dos anexos placentários, dificulta o combate a processos infecciosos uterinos, onde, 25 a 50\% das vacas com retenção desenvolvem metrite puerperal, agravando ainda mais o quadro clínico do animal (Fernandes et al., 2012).

Processos inflamatórios e infecciosos também podem desencadear falhas na expulsão dos anexos fetais, sendo que estas alterações podem variar de leves, com pouco envolvimento dos placentomas, até situações mais severas com necrose tecidual. Os placentomas necrosados adquirem bordas intumescidas e observa-se cooptação nas junções placentárias materno-fetais (Geoffrey, 1979). Focos de agentes patogênicos de qualquer parte do organismo podem ser transmitidos para a placenta durante a gestação. Esses patógenos podem disseminar-se a partir de infecções localizadas no casco, peritônio, úbere ou trato gastrintestinal atingindo assim a placenta. A infecção pode envolver poucas vilosidades cotiledonárias ou atingir toda a placenta (Kimura et al., 2002).

Dentre os agentes infecciosos causadores de infecções no trato reprodutivo de fêmeas bovinas podem citar inúmeros microrganismos. Dentre estes se destacam: Truepperela pyogenes (Zhang et al., 2014), Fusobacterium necrophorum (Bicalho et al., 2014), Streptococcus aureus, bacillus spp. (Sun et al., 2011), Tricomonas foetus (Palomares et al., 2017), Aspergillus fumigatos e Candida albicans (Florião \& Fraga, 2014). Werner et al. (2012) descreveram a Escherichia coli como principal patógeno uterino causador de infecção clínica do aparelho reprodutor da fêmea bovina.

Com a presença do processo inflamatório/infeccioso instalado no útero, os receptores presentes nas células endometriais passam a detectar os chamados padrões moleculares associados a patógenos (Williams et al., 2005). Essas substâncias, por ação direta são capazes de atuarem no eixo hipófisehipotálamo-gonadal afetando os pulsos de gonadotrofinas, tornando esses animais menos propensos a ovular e predispondo a formação de oócitos atrésicos no ovário (Williams et al., 2007; Williams et al., 2008).

Dessa forma, vacas acometidas por retenção de placenta podem apresentar diversas consequências secundárias a enfermidade como infecções uterinas, salpingite, peritonite e septicemia. Na esfera reprodutiva, a presença de processos infecciosos promove atrasos na involução uterina, retardo da atividade ovariana no pós-parto, aumento do intervalo entre parto e diminuição da taxa de concepção (Pereira et al., 2010). Outra falha celular está associada a quantidade reduzida de células trofoblásticas no início da gestação. Uma das funções destas células é a produção inicial de progesterona para o reconhecimento eficiente da gestação, uma vez que estas células não estão presentes em quantidades adequadas, podem-se diminuir os níveis circulantes de progesterona e prejudicar a maturação dos placentomas, favorecendo assim, a retenção placentária (Miguez et al., 2005; Pinto et al., 2008).

Assim, como a baixa de progesterona no início da gestação, concentrações séricas elevadas de progesterona antes do parto também estão associadas com retenção de placenta. O contrário ocorre com as concentrações de estradiol, de maneira que baixas concentrações estão associadas à retenção de placenta. Neste contexto, o estrógeno tem ação favorecendo o relaxamento da ligação entre as carúnculas e cotilédones. No entanto, a progesterona e estradiol precisam atuar de forma conjunta, pois, para que 
ocorra o desprendimento fisiológico da placenta é necessário que os níveis de estradiol aumentem concomitantes com a redução da progestágenos nas semanas que antecedem o parto (Takagi et al., 2002).

Outro fator hormonal aparentemente envolvido na retenção placentária é o cortisol. Em partos eutócicos, os níveis desse hormônio permanecem dentro dos padrões de normalidade para a espécie bovina. Em contrapartida, em animais submetidos a estresse no período final de gestação nota-se maior incidência de retenção placentária acompanhada de aumento, até duas vezes maiores, nas concentrações de cortisol. Este efeito pode estar relacionado com o efeito imunossupressor do cortisol, que impede a quimiotaxia celular para a região da ligação carúncula-cotilédone (Santos \& Marques Júnior, 1995).

As prostaglandinas também exercem papel importante na expulsão da placenta nas fêmeas bovinas. Segundo Stocker \& Waelchli (1993), as vilosidades coriônicas de vacas com retenção placentária produzem prostaglandinas do tipo E, em contrapartida as vacas sem retenção placentária sintetizam prostaglandina F2 $\alpha$. Neste contexto, com a inibição da síntese de prostaglandina F2 $\alpha$ promove um bloqueio nos mecanismos de expulsão da placenta em tempo hábil.

\section{Sinais clínicos}

O sinal clínico mais comum em vacas é a presença de envoltórios pendentes na vulva, entretanto, estes podem permanecer no útero e não estarem visíveis durante a inspeção visual, o que pode comprometer o diagnóstico e o estado geral do animal. Os sinais mais comumente relatados são: cólicas de intensidade alternada de acordo com o tempo decorrido, esforço expulsivo e a partir do terceiro dia inicia-se a putrefação das membranas uterinas e liberação de fluxo vulvar fétido de coloração cinzenta amarelada (Pereira et al., 2010). A evolução da retenção nos próximos dias é caracterizada por metrite séptica, anorexia, depressão, hipertermia e diminuição na produção de leite, sendo relatados casos de hipogalaxia e agalaxia. Na maioria dos casos de retenção de placenta, apenas o histórico de parto recente, juntamente com a presença de anexos fetais presentes na vulva já é suficiente para fechar o diagnóstico. Caso tais anexos não estejam presentes na vulva, podem ser realizados exames de palpação transretal e transvaginais (Prestes \& Landim-Alvarenga, 2017).

Durante a palpação transretal, o útero com a placenta retida revela-se pouco involuído, com certa distensão e flacidez. Pode ocorrer o acúmulo de líquido em casos avançados, o qual pode não estar presente ao início da patologia. A palpação transvaginal permite avaliar rapidamente o conteúdo uterino, quanto à quantidade, cor, viscosidade e odor, além de quantificar a área da placenta que se encontra retida. Ao exame ultrassonográfico, as membranas retidas aparecem como áreas hiperecóicas dentro do lúmen uterino (Agrimani et al., 2011).

\section{Tratamento}

Uma grande variedade de protocolos tem sido empregado no tratamento da retenção de placenta, no entanto, muitos estão questionados atualmente. O objetivo principal do tratamento deve ser a prevenção de futuras complicações, que podem comprometer a vida e o bem-estar geral do animal (Pereira et al., 2010). No entanto, não é recomendada a remoção manual da placenta, pois esta manobra pode acarretar várias complicações, tais como: hemorragia, septicemia, ruptura uterina e retardo na involução (Agrimani et al., 2011). A realização de lavagem uterina também é questionada, pois não é possível a retirada total do liquido introduzido, aumentando deste modo, o conteúdo uterino, o que retarda a involução (Nobre et al., 2012).

A aplicação de ocitocina apresenta eficácia discutida na literatura, sendo indicada apenas para casos com presença de inércia uterina, sendo que esta não é uma das principais causas para a retenção placentária, embora esta seja uma terapia muito utilizada pelos profissionais a campo (Prestes \& Landim-Alvarenga, 2017). Segundo Fernandes et al. (2012), o uso de prostaglandinas associadas a antibioticoterapia aceleram a involução uterina, previnem infecções e melhoram a fertilidade das vacas, reduzindo os índices de retenção de placenta. A utilização de estrógenos em doses fracas é referida como benéfica nos casos de retenção por inércia uterina, visto que este hormônio aumenta a sensibilidade do miométrio à ocitocina. Além disso, o estrógeno promove maior aporte sanguíneo ao útero, aumentando consequentemente o tônus muscular do miométrio e a atividade fagocitária, necessárias à separação 
placentária. Em contrapartida, o aumento de irrigação sanguínea no útero favorece a absorção de toxinas, possivelmente presentes em casos associados a infecções (Pereira et al., 2010).

O tratamento precoce com antibióticos sistêmicos em vacas com placenta retida é importante pois diminuem o risco de infecções uterinas associadas (Drillich et al., 2006). O cloridrato de oxitetraciclina é a droga comumente utilizada. Também são utilizadas antibioticoterapia com penicilina, gentamicina e atualmente tem sido empregado o ceftiofur, minimizando o descarte de leite por resíduos (Fernandes et al., 2012). Lefebvre \& Stock (2012) também descrevem a eficácia da utilização de enrofloxacina no tratamento de infecções uterinas.

A utilização de suplementação parenteral de vitaminas também pode ser uma alternativa para reduzir os casos de retenção placentária, neste contexto Leblanc, LeBlanc et al. (2002) utilizaram injeção subcutânea de vitamina E e Selênio, onde observaram redução significativa na incidência da enfermidade.

Devido sua origem multifatorial, nenhuma medida específica será eficiente para a prevenção da retenção de placenta. Recomenda-se minimizar ao máximo o estresse e aumentar a imunidade do rebanho, principalmente no período de transição, além de manter os animais bem nutridos e vacinados, impedindo problemas de subnutrição ou doenças reprodutivas infecciosas. Levando-se em conta as complicações possivelmente geradas pela retenção de placenta, tem-se um prognóstico bom para a vida, porém, reservado para a reprodução (Pereira et al., 2010).

\section{Considerações finais}

A ocorrência da retenção de placenta é considerada um evento comum e vários fatores contribuem para o desenvolvimento desta enfermidade acarretando diversos problemas secundários ao rebanho bovino. No entanto, há poucos estudos e levantamentos sobre os reais custos desta enfermidade em propriedades brasileiras. Cabe aos médicos veterinários atuantes, a conscientização sobre as principais causas de retenção placentária em bovinos, assim como o emprego de medidas de manejo preventivas a esta enfermidade.

\section{Referências bibliográficas}

Agrimani, D. S. R., Rui, B. R., Cruz, I. V., Romano, R. M. \& Lopes, H. C. (2011). Retenção de Placenta em Vacas e Éguas: Revisão de Literatura. Revista Cientifica Eletrônica de Medicina Veterinária, 9(16), 1-12.

Bicalho, M. L. S., Lima, F. S., Ganda, E. K., Foditsch, C., Junior Meira, E. B. S., Machado, V. S., Bicalho, R. C. (2014). Effect of trace mineral supplementation on selected minerals, energy metabolites, oxidative stress, and immune parameters and its association with uterine diseases in dairy cattle. Journal of Dairy Science, 97(7), 4281-4295.

Camargos, A. S., Gioso, M. M., Reis, L. S., Costa, I. F., Ferraz, M. C. \& Oba, E. (2013). Ocorrência de distúrbios da gestação, parto e puerpério em vacas leiteiras. Revista Científica Eletrônica de Medicina Veterinária, 20, 1-11.

Drillich, M., Mahlstedt, M., Reichert, U., Tenhagen, B. A. \& Heuwieser, W. (2006). Strategies to improve the therapy of retained fetal membranes in dairy cows. Journal of Dairy Science, 89(2), 627635.

Fernandes, C. A. C., Figueiredo, A. C. S., Ferreira, A. M. \& Sá, W. F. (2000). Variação sazonal da incidência de retenção de placenta em rebanhos leiteiros no sul do estado de Minas Gerais. Revista Brasileira de Ciência Veterinária, 7(3), 179-181.

Fernandes, C. A. C., Palhão, M. P., Ribeiro, J. R., Viana, J. H. M., Gioso, M. M., Figueiredo, A. C. S., Costa, D. S. (2012). Associação entre oxitetraciclina e cloprostenol no tratamento de vacas leiteiras com retenção de placenta. Revista Brasileira de Ciência Veterinária, 19(3), 178-182.

Florião, M. M. \& Fraga, M. E. (2014). Microbiota fúngica de fluidos cérvico-vaginal de bovinos de uma criação orgânica em região tropical. Brazilian Journal of Veterinary Medicine, 36(1), 85-89.

Geoffrey, H. A. (1979). Reprodução e obstetrícia em veterinária: Retenção das membranas fetais. Rio de Janeiro, Brasil: Guanabara Koogan. 
Gross, T. S., Williams, W. F. \& Moreland, T. W. (1986). Prevention of the retained fetal membrane syndrome (retained placenta) during induced calving in dairy cattle. Theriogenology, 26(3), 365-370.

Grunert, E., Birgel, E. H. \& Vale, W. G. (2005). Patologia e clínica da reprodução dos animais mamíferos domésticos: ginecologia: Varela.

Horta, A., Barbas, J., Marques, C., Baptista, M., Vasques, M., Pereira, R., Cavaco-Gonçalves, S. (2010). Improvement of fertility in artificially inseminated ewes following vaginal treatment with misoprostol plus terbutaline sulphate. Reproduction in Domestic Animals, 45(6), e412-e416.

Kimura, K., Goff, J. P., Kehrli, M. E. \& Reinhardt, T. A. (2002). Decreased neutrophil function as a cause of retained placenta in dairy cattle. Journal of Dairy Science, 85(3), 544-550.

Laven, R. A. \& Peters, A. R. (1996). Bovine retained placenta: aetiology, pathogenesis and economic loss. Veterinary Record, 139(19), 465-471.

LeBlanc, S. J., Duffield, T. F., Leslie, K. E., Bateman, K. G., TenHag, J., Walton, J. S. \& Johnson, W. H. (2002). The effect of prepartum injection of vitamin $\mathrm{E}$ on health in transition dairy cows. Journal of Dairy Science, 85(6), 1416-1426.

Lefebvre, R. C. \& Stock, A. E. (2012). Therapeutic efficiency of antibiotics and prostaglandin F2 $\alpha$ in postpartum dairy cows with clinical endometritis: an evidence-based evaluation. Veterinary Clinics: Food Animal Practice, 28(1), 79-96.

Markusfeld, O. (1984). Factors responsible for post parturient metritis in dairy cattle. The Veterinary Record, 114(22), 539-542.

Miguez, P., Cunha, M., Marques, B., Bertan, M. \& Binelli, M. (2005). Combination of estradiol-17 and progesterone is required for synthesis of PGF2 $\alpha$ in bovine endometrial explants. Animal Reproduction, 2(3), 172-177.

Nobre, M. M., Azevedo, R. A., Campos, E. F., Lage, C. F. A., Glória, J. R., Saturnino, H. M. \& Coelho, S. G. (2018). Impacto econômico da retenção de placenta em vacas leiteiras. Pesquisa Veterinária Brasileira, 38(3), 450-455.

Nobre, M. M., Coelho, S. G., Haddad, J. P. A., Campos, E. F., Lana, A. M. Q., Reis, R. B. \& Saturnino, H. M. (2012). Avaliação da incidência e fatores de risco da retenção de placenta em vacas mestiças leiteiras. Arquivo Brasileiro de Medicina Veterinária e Zootecnia, 64(1), 101-107.

Palomares, R. A., Hurley, D. J., Crum, L. T., Rollin, E., Collop, T., Williard, A., Corbeil, L. B. (2017). Serum, uterine, and vaginal mucosal IgG antibody responses against Tritrichomonas foetus after administration of a commercial killed whole $\mathrm{T}$ foetus vaccine in beef cows. Theriogenology, 87, 235241.

Pereira, E. S., Pimentel, P. G., Queiroz, A. C. \& Mizubuti, I. Y. (2010). Novilhas leiteiras (Vol. 1). Fortaleza, Ceará: Graphiti Gráfica e Editora Ltda.

Pinto, L. M., Ambrósio, C. E., Teixeira, D. G., Araújo, K. P. C., Kfouri Júnior, J. R., Morini Junior, J. C., Martins, D. S. (2008). Comportamento das células trofoblásticas gigantes na placenta de vacas Nelore (Bos indicus-Linnaeus, 1758). Revista Brasileira de Reprodução Animal, 32(2), 110-121.

Prestes, N. C. \& Landim-Alvarenga, F. C. (2017). Obstetrícia veterinária. Rio de Janeiro, Brasil: Guanabara Koogan.

Santos, R. L. \& Marques Júnior, A. P. (1995). Retenção de placenta em bovinos. Caderno Técnico da Escola Veterinária UFMG, 15, 37-52.

Stocker, H. \& Waelchli, R. O. (1993). A clinical trial on the effect of prostaglandin F2 alpha on placental expulsion in dairy cattle after caesarean operation. The Veterinary Record, 132(20), 507-508.

Sun, D.-b., Rui, W., He, X.-j., Shuang, W., Lin, Y.-c., Xu, H., Yang, K.-1. (2011). Development of a multiplex PCR for diagnosis of Staphylococcus aureus, Escherichia coli and Bacillus cereus from cows with endometritis. Agricultural Sciences in China, 10(10), 1624-1629.

Takagi, M., Fujimoto, S., Ohtani, M., Miyamoto, A., Wijagunawardane, M. P. B., Acosta, T. J., . Sato, K. (2002). Bovine retained placenta: hormonal concentrations in fetal and maternal placenta. Placenta, 23(5), 429-437. 
Werner, A., Suthar, V., Plöntzke, J. \& Heuwieser, W. (2012). Relationship between bacteriological findings in the second and fourth weeks postpartum and uterine infection in dairy cows considering bacteriological results. Journal of Dairy Science, 95(12), 7105-7114.

Williams, E. J., Fischer, D. P., Noakes, D. E., England, G. C. W., Rycroft, A., Dobson, H. \& Sheldon, I. M. (2007). The relationship between uterine pathogen growth density and ovarian function in the postpartum dairy cow. Theriogenology, 68(4), 549-559.

Williams, E. J., Fischer, D. P., Pfeiffer, D. U., England, G. C. W., Noakes, D. E., Dobson, H. \& Sheldon, I. M. (2005). Clinical evaluation of postpartum vaginal mucus reflects uterine bacterial infection and the immune response in cattle. Theriogenology, 63(1), 102-117.

Williams, E. J., Sibley, K., Miller, A. N., Lane, E. A., Fishwick, J., Nash, D. M., Sheldon, I. M. (2008). The effect of Escherichia coli lipopolysaccharide and tumour necrosis factor alpha on ovarian function. American Journal of Reproductive Immunology, 60(5), 462-473.

Zhang, D.-X., Tian, K., Han, L.-M., Wang, Q.-X., Liu, Y.-C., Tian, C.-L. \& Liu, M.-C. (2014). Resistance to $\beta$-lactam antibiotic may influence nanH gene expression in Trueperella pyogenes isolated from bovine endometritis. Microbial Pathogenesis, 71, 20-24.

Recebido: 6 dezembro, 2018 .

Aprovado: 27 dezembro, 2018.

Publicado: 21 janeiro, 2019.

Licenciamento: Este artigo é publicado na modalidade Acesso Aberto sob a licença Creative Commons Atribuição 4.0 (CC-BY 4.0), a qual permite uso irrestrito, distribuição, reprodução em qualquer meio, desde que o autor e a fonte sejam devidamente creditados. 